Summary.-The only pathologic finding suggestive of leukemic disease is the condition of the lymph glands. This resembles the gland picture seen in some cases of lymphosarcoma (aleukemic leucoblastoma?) or that of a lymphatic leukemia minus the increase of mononuclear elements in the blood. The spleen picture is of the same type as that of the splenic fibrosis of splenic anemia. Counts made of the leucocytes in the vessels of all the sections show an unusually high percentage of mononuclears. Because of the fixation, these cells could not be satisfactorily studied. There is, however, nowhere any increase of leucoeytes in the vessels suggesting the existence of a leukemia.

The calcification existing in the kidney is remarkable for its extent. It would suggest the occurrence of an intoxication causing degeneration or necrosis of the epithelium of the convoluted tubules followed by deposit of lime salts, such as occurs in poisoning with mercuric chlorid, chromates, etc.

Remarks.-The postmortem findings in this case are very interesting in connection with the experimental work that has been done by $\mathrm{H}$. Heinecke, ${ }^{3}$ and also the work now being done by Warthin which he will soon publish. Heinecke found that a brief exposure of mice, rabbits and dogs to the rays induces a distinct destructive process in the lymph follicles. With an exposure too brief to induce changes in the skin, he could cause a distinct destruction of the nuclei of the leucocytes in the follicles of the spleen, leading to their almost complete disappearance. Analogous processes took place in other Iymphoid elements. His remarks on the changes in the bone marrow are not clear except that some destruction of lymphoid elements took place. These experiments might suggest a physiologic basis for the use of the $x$-ray in leukemia, so far as the excess of white cells in the circulating blood and the presence of abnormal cell elements are concerned, and they compare most favorably with the results in our case. Undoubtedly the $x$-ray has a selective action, apparently affecting tissue undergoing pathologic hyperactivity and causing degeneration and necrosis of such tissue; however, the damage done is apparently greater than the good.

Dr. Warthin, in summing up the pathologic findings, says: "If any conclusion is warranted from the study of the specimens, it would seem to be that the $x$-ray treatment has resolved the leukemic condition into an aleukemic state, but that the essential disease process, as evidenced by the condition of the lymph glands, is still active. The leucocytes have been removed from the general circulation and from the areas of infiltration, the spleen presenting the characteristics of a chronic fibrosis. The part played by the latter would appear to be secondary. The remarkable condition of the kidneys offers room for some speculation as to the source of a toxin. Such might result from the destruction of enormous numbers of Ieucocytes."

It is much to be regretted that no specimen of bone marrow was obtained, for, as we believe this disease to be primarily in the bone marrow, we can come to no real conclusion until this part of the subject has been thoroughly studied.

It is to be hoped that the stimulation this form of treatment has given workers may at least lead to some conclusion as to the cause of this most interesting disease.

\section{A CASE OF MACROCHEILIA}

DUE TO ENLARGEMENT OF THE MUCOUS GLANDS OF THE LIP.

\section{IRVIN LINDENBERGER, M.D.}

FRENCH LICK, IND.

This condition may be due to one or several causes. With the exception of inflammatory affections, neoplastic growths occupy a prominent position. With inflammatory thickening there exists an enlargement not only of the glands but of the tissues of the whole lip, and affecting one or both lips; there is

3. Münchener med. Wochenft., May 3, 1904. no increase in the number of glands affected. Congenital dilatation of the lymphatic vessels, which is, more strictly speaking, an overgrowth when occurring in the tongue, produces macroglossia; when occurring in the lip, labium and other subcutaneous parts it is known as macrocheilia. Acquired lymphangiectasis is most commonly observed in the lower extremities and in the external genitals, being due to an obstruction of some nature and characterized by hyperplasia of the skin and subcutaneous tissues, producing the condition known as elephantiasis. Fraenkel ${ }^{1}$ states that prior to a case reported by him, macrocheilia due to a neoplasm of the mucous glands of the lips was unknown. This case was more fully reported by Dr. Daniel N. Eisendrath of Chicago, ${ }^{2}$ with a case of his own.

From the photograph of the present case, it will be noticed that the enlargement is only of the upper lip. This enlarge.

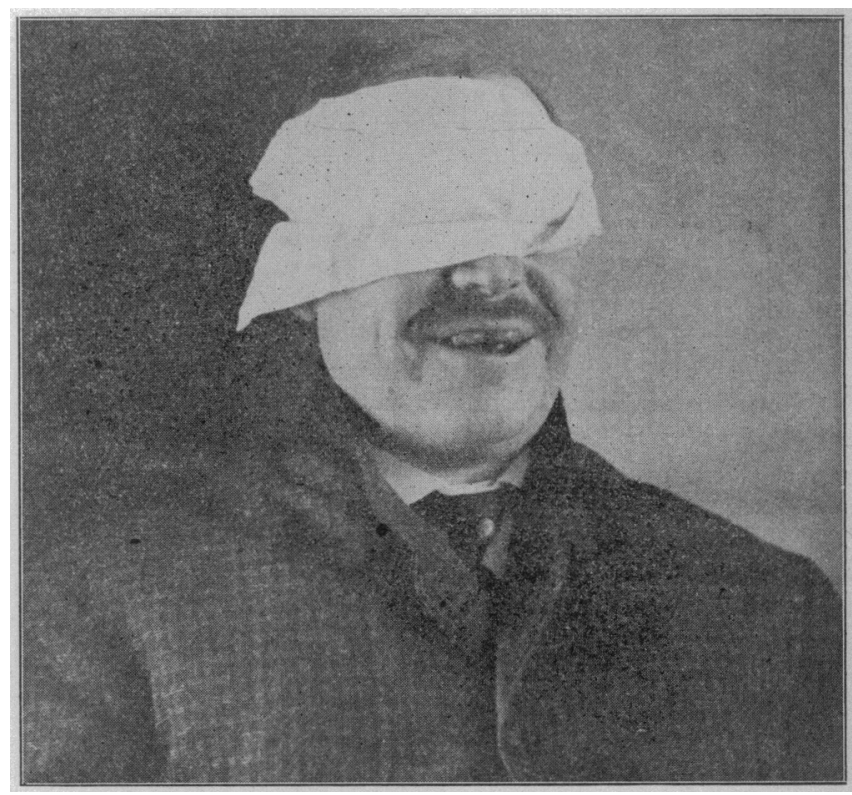

ment was especially noticeable in talking and laughing. On palpation, the lip was found to be soft and smooth, but on pressure there was a slight "shotty" feel in one or two glands on each side of the median furrow. The condition dated from a blow in the mouth, received about fifteen years previously. There has been no appreciable enlargement in the past ten years. His general health has always been good; there is no history of any specific trouble. A wedge-shaped incision disclosed a number of small glands, slightly smaller than buckshot, on each side. They were removed and the mucous mem. brane was sutured. Healing was prompt and the cosmetic effect was good.

1. Arch. für klinische Chirurgie, vol. xliv, 1892

2. Annals of Surgery, September, 1904.

Lowering of the Arterial Pressure Reliable Danger Sign in Chloroform Anesthesia.- J. Tissot of Paris has been studying on dogs the relations between the moditications in the arterial pressure and the toxic action of enloroform on the heart. The arterial pressure is a reliable index of the contracting power of the heart. We know that fatal accidents from chloroform are due to the toxic action of the drug on the heart or on the nerve centers controlling its action. He found that the dogs never displayed any threatening symptoms as long as the arterial pressure was above $100 \mathrm{~mm}$. $\mathrm{Hg}$, but respiratory arrest occurred whenever the pressure dropped to $60 \mathrm{~mm}$. Cardiac syncope occurred if it fell near or below $50 \mathrm{~mm}$. $\mathrm{Hg}$. The chloroformization in his experiments was always slow and gradual. Tissot believes that these data will be fownd to apply also to man, and that by watching the arterial pressure we will be able to detect impending danger long beforc it is revealed by any other sign. 'Tissot's communication was presented at the meeting of the Paris Academie des Sciences, February 20, 1905 . 